\title{
From Working Tourists to Permanent Residents: Experiences of Migrant Workers with Youth Mobility Schemes in Canada
}

\author{
Mylène Coderre ${ }^{1}\left[0\right.$. Delphine Nakache ${ }^{2}$
}

Accepted: 3 July 2021 / Published online: 20 July 2021

(C) The Author(s), under exclusive licence to Springer Nature B.V. 2021

\begin{abstract}
In OECD countries, international mobility programs such as youth mobility schemes have gained popularity over the last years. In Canada, the International Mobility Program (IMP) has become the dominant mechanism for temporary migrant workers to enter into Canada, and yet, this stream has operated largely below the radar of public debate. Our article focuses on International Experience Canada (IEC), a category of the IMP allowing young people to work and travel in Canada. Based on documentary, survey and interview material with IEC participants, we investigate how the IEC regulatory framework influences the employment and immigration experiences of these young workers. We argue that, instead of being a form of privileged youth mobility, the IEC is composed of multiple regulations resulting in significant variations in conditions of admission and stay among migrant workers. This situation leads to differentiated employment conditions and uneven transitions to permanent residence.
\end{abstract}

Keywords International Mobility Program (IMP) $\cdot$ International Experience Canada (IEC) · Youth mobility scheme $\cdot$ Working Holiday $\cdot$ Precarious migration

\section{Introduction}

Over the last decades, OECD countries have developed competitive migration regimes to address their increasing demand for migrant workers (OECD, 2019). While their policies have traditionally been geared towards the temporary admission

Mylène Coderre

mylene.coderre-proulx@uottawa.ca

Delphine Nakache

delphine.nakache@uottawa.ca

1 School of International Development and Global Studies, University of Ottawa, Ottawa, Canada

2 Faculty of Law (Common Law Section), University of Ottawa, Ottawa, Canada 
of "guest-workers", recently, many programs have been designed to attract internationally mobile professionals (Cerna \& Czaika, 2016; Shachar \& Hirschl, 2013). Despite variations across jurisdictions, a common feature of these international mobility programs is that, in contrast to traditional temporary labour migration programs, they are not tied to, or motivated by, domestic labour shortages (Pellerin, 2017). They are generally shaped by trade, investment or cultural agreements negotiated between states and are intended to advance a broader range of national interests. The expansion of youth mobility schemes in OECD countries is an example of this newer generation of international mobility programs. There is no widely accepted definition of what constitutes a youth mobility scheme, but it generally refers to programs combining both temporary work and travel opportunities for young adults (Oommen, 2019; Consterdine, 2019; OECD, 2019, 120). Youth mobility schemes are regulated through bilateral agreements aimed at providing reciprocal opportunities for citizens of the state parties to these agreements. Working Holiday (WH) is the predominant form of these schemes, accounting for $10 \%$ of all migrant workers into OECD countries. Australia, the USA and New Zealand are the top destinations, but a significant increase of WH makers has also been observed in Canada, Japan, Ireland, Korea and Denmark (OECD, 2019, 27).

In Canada, research about international mobility programs is extremely limited, despite the fact that they have become the dominant mechanism for migrant workers to work in this country (see for exception Pellerin, 2017 and Vosko, 2020). Temporary foreign workers (TFWs) can enter into Canada through two overarching categories: the Temporary Foreign Worker Program (TFWP) and the International Mobility Program (IMP). One of the main differences between the two categories is that the TFWP is considered a "last resort for employers to fill jobs for which qualified Canadians are not available", whereas the IMP is used "to advance Canada's broad economic and cultural national interest" (ESDC, 2014, 1). Unlike the TFWP, the IMP does not require a pre-verification by the government to confirm the need for hiring a TFW. Another difference is that the work permits granted under the TFWP are traditionally employer-specific, whereas those under the IMP are mostly-but not exclusively - open, thereby enabling an individual to work for any employer. In 2014-2016, the Canadian government introduced a series of changes to the TFWP, making it increasingly difficult for employers to hire a TFW through this program (i.e. caps and restrictions to work authorizations, higher fees for employers and reduction of permit duration) (El Assal \& Sweetman, 2016). This has led to an increasing number of employers using the IMP to circumvent the restrictions imposed by the TFWP (Gilbert, 2017). With 306,960 work permits granted in 2019, in comparison to 98,335 for the TFWP (IRCC, 2020a), the IMP has become the main admission program for TFWs. While its compliance system is limited compared to the TFWP, the IMP's regulatory framework is much more complicated. Indeed, in 2020, there were approximately 70 admission categories within the IMP, each with specific conditions and requirements.

One of the largest categories of the IMP, accounting for $20 \%$ of all IMP permit holders in 2019, is International Experience Canada (IEC), which is dedicated to youth mobility (IRCC, 2021). It allows young citizens of countries that have signed a youth mobility agreement with the Canadian government to come to Canada 
through the Working Holiday (WH), the Young Professionals (YP), or the Co-op Internship (Co-op) programs. The number of workers annually admitted under the IEC doubled between 2007 and 2019 to reach 61,660 (IRCC, 2021). Canada is now the fourth OECD country with the highest number of WH makers (OECD, 2019, 27). Despite its growing importance, this program has operated largely below the radar of public debate (Helleiner, 2017). Most of the focus within the Canadian literature is on migrant workers admitted under the TFWP, who are mostly workers in "low-skilled" occupations, and on their precarious status and exploitative living and working conditions (Goldring \& Landolt, 2013; Marsden, 2018; Nakache \& Dixon-Perera, 2015). This lack of attention may be explained by the fact that such programs have been constructed as privileged mobility in which workers are thought to have high-skill qualifications and to enjoy better employment and immigration conditions (Pellerin, 2017, 357). However, the emerging set of literature on youth mobility schemes offers a more complex image and leads us to question the "taken for granted' approach on their privileged positionality" (Oommen, 2019, 1).

In this article, we draw on documentary data a survey and in-depth interviews to explore how the International Experience Canada (EIC), as an entry category with specific conditions of admission and stay, shapes the integration of IEC permit holders into the labour market and their capacities to transition to a permanent status. We argue that, instead of being a form of privileged mobility, the IEC is composed of multiple regulatory frameworks that produce a hierarchy of statuses and create differentiated pathways into and out of precarity among participants. We first situate our case study within the literature of youth mobility schemes and present the concepts of "temporary-permanent divide" (Rajkumar et al., 2012) and "precarious legal status" (Goldring \& Landolt, 2013; Goldring et al., 2009), which inform this analysis. We then explain the research methodology and discuss our research findings. We show how the IEC has become a complex program with differentiated conditions of admission and stay among participants. Second, we discuss the prevalence of work over travel in IEC participant experiences, which suggests that this program is evolving into a new channel for temporary labour migration. Finally, we show that the bilateral nature of IEC leads to important variations in immigration opportunities among IEC workers and discuss how, for those with greater access to permanent residence, seeking permanent residence is primarily considered as a means to "secure" their legal status, not to settle in the country.

\section{Youth Mobility, Temporariness and Precarity}

Youth mobility schemes are a form of migration at the crossroad of tourism and work migration. Because of their association with tourism, young migrants admitted under these schemes "remain politically hidden", and little attention is given to their migratory experiences (Consterdine, 2019, 40). Most research on youth mobility schemes, and Working Holiday (WH) more particularly, have focused on the leisure dimension of these programs, with the work component being solely approached as a means to live overseas social and cultural experiences (Uriely, 2001; Wilson et al., 2010). By referring to WH makers as "working tourists", "sojourners" or 
"backpackers", this literature emphasizes the temporariness, recreational and privileged dimensions of their international mobility (Fang et al., 2020; Ho et al., 2014; Rice, 2010; Yang \& Wen, 2016; Zhu et al., 2020). However, the limited research documenting their employment patterns reveals a different picture regarding youth mobility experiences. In Australia for example, where the number of WH makers now exceeds 200,000, more than all other TFWs programs (OECD, 2019, 211), several studies have emphasized the increasing importance of work over tourism during these migrants' stay, a shift driven by structural demand for a younger, more flexible and low-cost workforce (Reilly, 2015; Reilly et al., 2018; Roberston, 2014; Tan \& Lester, 2012). More particularly, the requirement of completing 3 months of "specified work" in agriculture, mining and construction industries in order to get a second WH visa illustrates how certain sectors of the Australian economy now rely heavily on these youth workers (Australia Department of Home Affairs, 2018). In the UK, Oomen, (2019) has examined the ways employment experiences under the youth mobility scheme differ according to gender, race, nationality and language. She finds that female participants are concentrated in feminized service sectors and that participants from East Asia are less likely to find a job that matches their qualifications than participants from the Old Commonwealth countries. In Canada, the few scholarly works available only examine the WH program and highlight that WH makers tend to concentrate in "low-skilled" positions (see Hélin, 2017 for French WH makers; Yoon, 2014, 2015 for Korean WH makers; Smith \& Staveley, 2014 in Banff National Park). These insights regarding precarious employment and inequalities in youth mobility experiences have important implications that go beyond the field of employment. Indeed, most OECD countries have recently adopted policy frameworks to facilitate onshore transitions from a temporary work status to a permanent residence (PR) status (Haan et al., 2020; Hawthorne, 2010; OECD, 2019a). Research reveals that the occupational position held by these migrants is a major factor facilitating or hindering their transition to PR (Haan et al., 2020; Nakache \& Dixon-Perera, 2015; Rajkumar et al., 2012). Thus, a more critical assessment of youth mobility schemes through the lens of labour migration is needed. Important questions remain about the experiences of these migrant workers in destination countries. What are the conditions of admission and residence associated with their status? What are their positions within labour markets? What are the factors shaping their occupational position and employment conditions? Do they/can they transition from temporary to permanent status and if so, how are these legal status trajectories experienced?

Literature focusing on how state policies shape migrants' abilities to remain or transition to a legal status category, and to access specific rights, is useful to address the questions above. Legal status categories form the basis of the rights granted to an individual regarding access to employment, settlement and public services. Rajkumar et al. (2012) used the notion of a "temporary-permanent divide" to illustrate how migration policies act as "paper borders" by shaping a hierarchy of statuses among migrant workers, ranging from being temporarily temporary to permanently temporary. According to these authors, the capacity to transition to a more secure status and access greater entitlements in the host country depends primarily on migrants' skills classification and resulting entry categories $(2012,505-506)$. Legal categories with restrictive forms of 
temporariness are normally associated with precarious legal status for migrants. Developed by Goldring and Landolt, this concept refers to "authorized and unauthorized forms of non-citizenship that are institutionally produced and share a precarity rooted in the conditionality of presence and access [to entitlements]" (Goldring \& Landolt, 2013, 3 ). It is generally characterized by any of the following situations: absence of a work authorization or residence permit, the right to be in the country conditional to a third party (e.g. employer or spouse), or not having access to services granted to permanent residents, such as education or health coverage (Goldring et al., 2009, 241). However, it is not a fixed position because migrants, depending on their variable capacities to meet the immigration conditions, can "climb the ladders" by gaining a more secure status or can experience chutes into more precarity (Landolt \& Goldring, 2013, 15; Goldring \& Landolt, 2021). Legal status categories also condition the integration of migrant workers into the labour market. By imposing conditions of admission and residence (skill requirement, type of work permit, duration of stay), they contribute in producing specific categories of workers deemed as a "good fit" for certain types of jobs and segments of the labour market (Anderson, 2010; Goldring \& Landolt, 2013). Individuals living with a precarious legal status are thus more likely to be found in precarious employment where there is a lack of income security, poor workplace standards and little control over the working conditions (Procyk et al., 2017; Standing, 2011). This literature captures the range of legal trajectories and highlights the differentiated migratory pathways according to entry categories. What is less explored, however, is how state policies can produce, within one entry category, various legal statuses with differentiated access to entitlements. The IEC is an important illustration of this trend; yet, it has operated largely below the radar of public debate. In fact, none of the few studies available on the IEC has provided an insight into the complex regulatory framework surrounding this program, or its impacts on migrants' lived experiences in Canada. In her article on the Canada/Ireland youth mobility agreement, Helleiner pointed out this knowledge gap and concluded that "much more needs to be known about onthe-ground experiences of International Experience Canada migrants differentiated by quota, lengths of stay and a racialized Canadian labour market" $(2017,313)$. With this in mind, we decided to carry out specific research on the IEC, one that investigates its regulatory framework and sheds light on the varying work and immigration experiences of its participants. By looking into one specific stream of the IMP, our intention is to contribute to a better understanding of the ongoing transformations of Canadian labour migration policies.

\section{Research Methodology}

This research was conducted from 2017 to 2019 and draws on three data collection methods. ${ }^{1}$ First, we relied on documentary and statistical data obtained from Immigration, Refugees and Citizenship Canada (IRCC) to get a comprehensive

\footnotetext{
1 Because this research was conducted before the COVID-19 crisis, the findings do not consider the effects that the pandemic context may have had on the evolution of the EIC program and on the employment of these migrant workers.
} 
understanding of the IEC regulatory frameworks and a general portrait of IEC workers. We conducted in-depth desk research on the IRCC portal to collect information on each bilateral youth agreement (conditions of stay and admission, eligibility criteria, quota, year of signature, etc.). We also requested detailed statistics regarding the number of IEC workers admitted yearly from 2000 to 2019 in each IEC category, by age, gender, nationality and province of destination. Second, given the lack of information on IEC participants' immigration intentions and experiences, in 2018, we conducted online surveys with 36 IEC participants originating from various countries and working in different jurisdictions in Canada. ${ }^{2}$ We recruited participants by advertising our survey on social media (Facebook pages dedicated to the IEC). The survey provided information on the following: (1) reasons for applying to the IEC, (2) immigration intentions after the IEC, and (3) experiences in transitioning to PR, if relevant. Online surveys were complemented in the summer of 2018 by 10 1-h semi-structured interviews (in English and French) with IEC participants in Montreal (Quebec), ${ }^{3}$ the province with the highest number of IEC work permit holders (IRCC, 2021). Interview participants were mainly recruited through the surveys where they were asked to indicate, at the end of the questionnaire, if they wanted to take part in an interview as well. We also posted a call for participation on Facebook pages followed by IEC workers in Montreal. Interviews were aimed at understanding IEC participants' work experiences (i.e. was it easy to find a job; how did they find a job; what was their perceived employment conditions) and at investigating the specific reasons behind their decision to seek permanent residence and their experiences with pathways to PR (i.e. when did they become aware of any options to apply to PR; what factors led them to seek PR; if they had already applied to $\mathrm{PR}$, what challenges did they face in transitioning from a temporary to a permanent resident status). We also conducted one Skype interview with a representative from Pvtistes.net, a website whose objective is to assist Francophone IEC participants in their immigration process in Canada and abroad.We conducted this interview because all of the Francophone respondents identified Pvtistes.net as their primary source of information on the IEC. This interview allowed us to gain insights into the strengths and weaknesses of the programs, as well as potential policy improvements. All interviews were audio-recorded and coded following mixed methods of deductive and inductive research. A few coding categories were pre-determined according to our research objectives (work experience with IEC permit, immigration intentions and PR experiences). However, we conducted in-depth interviews because we believe that IEC participants are best positioned to inform research and policies, and that their views are a critical source of knowledge. Thus, we adopted an inductive analytical approach to code other themes that emerged from our discussion with IEC participants (original intentions; life in Canada; administration of the IEC program; risk and fear of losing status; policy recommendations and future plans). All migrant participants were treated as anonymous; their names in this article are pseudonyms.

\footnotetext{
${ }^{2}$ Survey participants were from France (14), UK (7), Australia (3), Germany (3), Belgium (2), Chile (1), Croatia (1), Ireland (1), Italy (1), New Zealand (1), Poland (1), USA (1).

3 Interview participants were from France (7), Chile (1), Poland (1) and the USA (1). Nationals from the USA are categorized as "Other IEC category" since they come through SWAP Working Holidays, a private organization, instead of a Youth Mobility Agreement.
} 
The qualitative component of our research cannot be considered as representative of the experience of all IEC workers in Canada. The number of workers interviewed and surveyed in this research is too low compared to the total population of IEC workers. Also, interviews were mainly conducted in French, in the province of Quebec. We therefore acknowledge biases in our research in terms of participant and location selection. However, our intention was to gain insight into the reality of this growing group of workers, and, given that previous literature has barely addressed this research topic, we believe that the views collected in this research-mainly from migrant participants - and the findings discussed below provide a valuable source of information.

\section{The IEC: A Complex, Fragmented and Opaque Regulatory Framework}

International Experience Canada (IEC) began in 1951 as a reconciliatory cultural exchange between Canada and Germany following World War II, and was extended in 1967 to other countries. To date, Canada has signed bilateral youth agreements with 36 countries in Europe, Asia and Latin America, which determine the conditions of mobility and the quota of participants (IRCC, 2020b). Within the complex institutional architecture of the International Mobility Program (IMP), IEC is situated under the "Reciprocal employment" category and comprises people admitted into Canada due to reciprocal agreements (e.g. youth and academic exchange programs). There are three types of visas within the IEC: Working Holiday (WH), Young Professionals (YP), and International Co-op (Co-op). WH is the most popular of the three categories, accounting for $67 \%$ of all IEC participants (IRCC, 2021). WH's official goal is to "fund vacation with temporary work in Canada" (IRCC, 2020b). The YP visa, for its part, is designed for candidates who want to "gain Canadian professional work experience to better compete in a global economy" and requires participants to obtain an employment offer classified as a "skilled job" before coming to Canada ${ }^{4}$ (IRCC, 2020b). Finally, Co-op is for students who are enrolled in a post-secondary institution in their country of origin and want to get work experience in their field of study in Canada. The last wo categories differ from the WH in three main respects. First, unlike the WH, the YP and Co-op categories are explicitly "skilled" migration streams, since they include requirements regarding participants' level of qualification. Second, workers of the YP and Co-op receive an employer-specific work permit, while the WH provides an open work permit allowing participants to work for any employer. Third, in the province of Quebec, where we conducted interviews, WH makers are not eligible for public health coverage, in contrast to YP participants who are admissible as part of their work placement. Co-op participants are only eligible to receive health coverage if their country of origin has signed a social security agreement with the Quebec government, as it has

\footnotetext{
${ }^{4}$ National Occupation Classification (NOC) is Canada's taxonomy classifying occupations in the labour market. Occupations under NOC 0 , A or B are "skilled" work and require tertiary education or a minimum of 2 years of training. Jobs classified as NOC C and D are considered "low-skilled" work and require a high school diploma or a maximum of 2 years of job-specific training.
} 
with France and Belgium (RAMQ, 2020). Because health is under provincial jurisdiction, eligibility requirements to public health coverage may vary in other Canadian provinces.

Except for the above regulations, all other conditions of admission and stay for IEC workers are set out within each bilateral agreement signed between Canada and the country of origin. Our compilation of immigration rules for the 35 partner countries reveals that the age eligibility, the types of visa available and the length of authorized stay vary greatly according to a participant's country of origin (IRCC, 2020b). For example, while in most cases, participants must be aged 18 to 35, for some participating countries, the age limit is 30 (e.g. UK, Belgium, Japan, South Korea). Additionally, while participants from most countries can apply under any of the three categories, those from Belgium, Denmark, Hong Kong, Italy, Japan, New Zealand, San Marino, South Korea and the UK can only come to Canada through the WH, and participants from the Netherlands and Switzerland can only participate under two categories (WH and YP for Dutch participants; YP and Co-op for Swiss participants). Workers from some countries can participate in the IEC only once (e.g. Hong Kong or Italy), while others can participate two times. Some are required to repeat their participation in a different category, while others are permitted to repeat the same category. For instance, for Switzerland, workers can repeat the same category twice, so long as their participation in the program takes place within the 18-month total limit. For Chile, workers can also repeat the same category, but there needs to be a 3-month break between the first and the second permit. IEC participants from certain countries (e.g. Italy) will receive a work permit of 6 months, while others will receive a work permit of 12, 18, 23 or 24 months. Most IEC participants can work anywhere in Canada, except Co-op participants from Austria, who must do an internship in the forestry, agriculture or tourism industry. Furthermore, in 2015, the IEC shifted from a first-come, first-served model to an invitation-based model. This means that applicants may receive an invitation in an early draw, or wait months before receiving an invitation, or never receive one at all. In fact, the chances of being invited vary greatly depending on the candidate's country quota (IRCC, 2019c; Moving2Canada, 2021).

One might expect that disparities between countries exist because these agreements are reciprocal; in other words, the same opportunities are available for young foreigners in Canada apply to young Canadians abroad. However, this is not always the case. For example, Australian citizens can work in Canada for 24 months under one of the three IEC categories. They are permitted to participate in the IEC twice, but their second participation must be in the Co-op category and cannot exceed 12 months. In contrast, Canadians are allowed to work in Australia with a WH visa, but only for 12 months. They can receive a second WH 12-month visa, but this visa is subject to them having completed 3 months of specified work in designated regions (Australia Department of Home Affairs, 2018). It is also worth noting that the total number of IEC participants coming to Canada is three times higher than the number of Canadians going abroad (IRCC, 2019a, 4).

Not surprisingly, disparities between bilateral agreements and important variations in immigration rules are difficult for both employers and workers to follow and have led to confusion among the IEC workers that we interviewed. This is 
compounded by a related concern that IEC rules change rapidly and without notice. In fact, any change to the IEC is only provided on the IRCC website through its Program Delivery Instructions and Updates, which are brief announcements to inform IRCC staff. Such information is made public "as a courtesy to stakeholders" (IRCC, 2019c), but it is clearly directed to civil servants (not migrant workers), as illustrated by the technical jargon used in these documents. Most participants in our research found that the information available on the IRCC website was not clear or straightforward, and they described trying to find out information from an IRCC representative on the phone as very difficult:

"It's very hard to reach the immigration hotline (...) They don't accept calls from outside of Canada. And I have a [foreign] number. So (...) I could only call from my work phone. And if you called thirty minutes after the hotline opened, you wouldn't be able to get through for the rest of the day, because they have so many people on hold. So, it was (...) very, very frustrating" (Allison from United States).

One interviewee even said that there is an "inside joke" among French IEC participants that IRCC officers are in fact "secret agents" because "there is no one to pick up the phone" (Laura from France). This issue was acknowledged in a recent report from the Auditor General of Canada which found that $70 \%$ of calls to the IRCC did not reach an agent (Office of the Auditor General of Canada, 2019, 4). The challenges associated with collecting and navigating accurate and up-to-date information about the IEC create an environment of uncertainty for IEC workers, a situation that is exacerbated by the fact that many employers are not familiar with the IEC rules. This is particularly stressful for workers with an employer-specific work permit, who accounted for one-third of all IEC workers in 2019 (IRCC, 2021). In our survey, seven participants were on an employer-specific work permit and two of them, who also participated in the interviews, explained that they found themselves in an uncertain situation because their employers didn't know how to renew their work permits. Not surprisingly, intermediaries have started filling in the gaps, as indicated by the fact that all migrant participants said they relied extensively on private websites such as Moving2Canada or pvtistes.net.

In sum, within a same entry category, we see that there are multiple conditions of admission and stay resulting in differentiated legal status (e.g. skills requirements, nature and duration of the work permit, ability to change from one status to another, authorized length of stay, entitlement to public health care). All these rules differ significantly for migrant workers admitted under the IEC category and this is problematic because they generate inequalities, with some migrants having more rights and fewer restrictions than others, which ultimately impact their legal status trajectories. This also complicates the administration of the IEC program, which is already extremely opaque, thereby creating an insecure environment for migrant workers. Findings on the complexity of navigating Canada's ever-changing programs and policies are not new (see, e.g. Nakache \& Dixon-Perera, 2015; Yoon, 2015), but our findings reiterate the need for greater transparency in this area. It is essential that IEC workers can form reliable expectations about eligibility requirements, the availability of programs, or their conditions of stay, especially in a context where the IEC is rising in importance and complexity. 


\section{International Experience Canada: Tourism or Precarious Employment?}

As discussed earlier, the few studies conducted with Working Holiday (WH) makers in Canada suggest that work is an important factor in their decision to come to Canada. Yoon, for instance, reports that the main motivations of Korean WH makers in Toronto are employment-related, and that the majority of them work full-time in the service industry $(2014,1019)$. In our research exploring the employment experiences of IEC participants, we found that-contrary to the presumption that WH makers aim to earn income to support their holiday in Canada-WH makers' motivations are to gain work experience, similar to those of workers in other categories (i.e. YP and Co-op permit holders, IRCC, 2019c). One-third of the survey respondents identified work experience as one of the main reasons for applying to the IEC. This was highlighted again during our interviews with migrant participants, where seven out of eight WH makers indicated that they held their permit primarily for work purpose, describing their life in Canada as a "standard" professional lifestyle, with work coming first and leisure and travel coming second. Interestingly, while the rationale behind the open work permit issued to WH makers is to allow them "to travel in Canada and work in order to supplement their financial resources" (IRCC, 2019c), the interviewees worked on a full-time basis with the same employer and had no time to travel. Two other interviewees, one under the YP and one under the Co-op, indicated that these categories were their second choice, because the quota for WH had been filled: "We applied to the WH, and he [the partner] was drawn. I applied again this year and the plan B was to come to Canada with the Co-op Internship" (Sandrine from France). Thus, even if the objectives of the three IEC categories are distinct on paper, our research suggests that the frontiers between them become increasingly blurred. There seems to be a growing disconnect between the IEC policy formulation and implementation, especially with respect to the WH category.

Clearly, conditions of admission and stay for WH makers from some countries are such that they provide participants with the opportunity to realize professional projects. For the key informant from Pvtistes.net, this is a specific advantage of the Canadian WH permit when compared to other WH programs abroad. For example, in Canada, for 24 out of 35 participating countries, the eligibility age for a WH permit is 35. In addition, most WH permits allow participants to work in Canada for 12 months or more and are renewable (IRCC, 2020b). In contrast, in Australia, participants' age limit is 30 for the majority of WH makers (except for Canadians, French and Irish) and they are not allowed to work for the same employer for more than 6 months. These immigration rules are closely connected to the country's economic plan, which is driven by the need for immigration to meet labour shortages, especially in "low-skilled" occupations (BDC, 2018; Desjardins Group, 2019). The particularly high demand for young workers is highlighted by the first evaluation of the IEC program, conducted by IRCC in 2019, which reveals that nearly half of the 3408 IEC workers surveyed work in two sectors where labour shortages were the most acute before the pandemic: food, accommodation services and retail trade 
(IRCC, 2019a, 27). Moreover, 80\% of these respondents reported working full-time (i.e. $30 \mathrm{~h} /$ week or more), with annual average employment earnings not exceeding $\$ 15,000$, making them the temporary resident group with the lowest income in Canada after international students (IRCC, 2019a, 24). This high demand for young migrant workers is illustrated by the important number of employers registered on pvtistes.net (near 3000 in December 2020), with food and accommodation being the most important categories of job offers.

In our research, although 31 out of 36 of our survey participants had a university degree, many of them, especially those with a WH visa, were employed in a job below their qualifications.

"I looked for a job in my field, in law, but so far I haven't found anything, I don't have enough work experience here (...) It seems this kind of job is not accessible here, maybe because I don't have a Canadian degree (...) but it is very easy to find a job even if it is not your dream job (...) even if my job is to work in a call center or a coffee shop (...) it's easy to earn money but it's also easy to lose your job" (Paulina from Poland).

"The job was very administrative, which was a little bit, I think, below wherecause, before I had worked as a specialist in communications, so that was a little bit of a step down. I knew that I wasn't going to get my dream job when I came here" (Allison from United States).

"In my country, I was an administrative assistant. I came here and I cleaned bathrooms and made beds in a hotel. (...) I worked for a temporary agency. (...) I was also working in a restaurant in the weekends, making coffee, drinks, but it was just the weekends, because they didn't pay me well. They paid me ten dollars under the table" (Lucia from Chile).

The importance of work over travel in WH experiences puts into question the rationale for excluding them from health care coverage in Quebec. This was a recurrent concern among our interviewees:

"I cannot have RAMQ [public health insurance in Quebec] because I have an open work permit. I find that YP is more simple because they arrive with an employer and have the RAMQ while among the WH makers, many ended up as waitress or in "jobines" [Quebec term for "precarious jobs"] without health insurance (...) Private insurance for WH makers only covers emergencies, so pregnancy or an operation not resulting from an emergency are not covered" (Laura from France).

Some WH makers also reported labour rights concerns, such as not having signed an employment contract or not being paid for training days: "I think they [employers] assume that because we are on a working holiday permit, we don't know that training should be paid" (Marion from France). In contrast to WH makers, YP and Co-op respondents occupied a "skilled" job related to their academic and professional background. However, they acknowledged that holding an employer-specific work permit presents its own risks since their working conditions partly rely on luck in having a "good" employer: "If you come into Canada with a YP (or Co-op), you have to choose 
your employer carefully because if you pick someone who is not good, you cannot change" (Claire from France). Co-op participants also occupy a grey area between foreign student and worker status, which makes them particularly vulnerable because their income is not guaranteed.

"It is not my Canadian employer who pays me but a training organization in France. The employer only reimburses local transportation fees (...) But clearly, I am not considered as an unpaid trainee here but an employee (...) If I got an international student status, I could work 20 hours per week, but I can't because I have a closed work permit" (Sandrine from France)

The strong demand for IEC workers and the key importance that they attach to employment during their stay indicates that this program is moving from a youth exchange program to a labour migration program. This raises issues regarding employment conditions as our participants experienced, to varying degrees, some kind of precarious employment. For YP and Co-op participants, the main concern lies in their employer-specific work permit, which makes their stay in Canada conditional to their relationship with their employer. Another layer of vulnerability for Co-op participants is that remuneration is not guaranteed because participation in the Coop-program is presented as an "internship opportunity". For WH makers, we observed a deskilling tendency resulting in lower wages and sometimes poor work conditions. If the open work permit provides more flexibility, it also comes with fewer rights (regarding access to health care, for example) and little job security. These findings highlight the importance of reassessing IEC policies to account for the recent labour market transformations and employment conditions associated with the program's growth, in order to ensure that IEC workers do not become an attractive pool of cheap and unregulated workforce, similar to what has been documented in other countries, such as Australia.

\section{Uneven Transitions to Permanent Residence}

In Canada, onshore transitions to permanent residence (PR) tripled between 2004 and 2014, with TFWs constituting the largest proportion of these transitions ( $\mathrm{Lu} \&$ Hou, 2017; OECD, 2016, 8). In 2018, 30\% of admitted permanent residents had previously held a temporary work permit in Canada (IRCC, 2019d, 15). Various policy changes account for the growth of onshore transitions from a temporary to a permanent status in Canada. For example, the Canadian Experience Class (CEC), implemented in 2008, represents an opportunity for TFWs with one year of "skilled" work experience in Canada, and proficiency in one of the two official languages, to apply for PR (Sweetman \& Warman, 2014). The expansion of provincial nominee programs, which allow provinces to select immigration applicants who meet economic needs, has also contributed significantly to this increase (Nakache \& Dixon-Perera, 2015). The province of Quebec, where we conducted interviews with IEC participants, has its own fast-track PR process. The Quebec Experience Program (PEQ), established in 2010, allows TFWs with full-time work experience in Quebec, and demonstrated intermediate knowledge of French, to apply to PR. Until July 2020, all TFWs with 1 year of work experience, regardless of their skill level, were eligible to 
apply to this program. Since then, eligibility criteria have been restricted to TFWs with 2 years of "skilled" work experience in Quebec (IFIQ, 2020). The few statistical studies available on TFWs' access to PR indicate that, traditionally, IEC participants have transitioned to PR in smaller numbers than other categories of TFWs (Lu \& Hou, 2017; Prokopenko \& Hou, 2018; IRCC 2019a, 26). However, very little is known about factors leading IEC participants to seek PR, or not, and factors impeding or facilitating their transition to PR.

A majority of the survey (19 out of 30 respondents who answered this question) and interview participants (8 out of 10) indicated that they considered applying for PR, or that they already were in the PR process. There are, however, important discrepancies in immigration experiences, as the capacity to transition to PR is heavily conditioned by the length of stay initially granted and the opportunity for workers to extend their stay. As discussed earlier, there are disparities in authorized lengths of stay among IEC participants, since some can stay in Canada for a maximum of 12 months, while others can stay for 18 months or 24 months. Those who have the right to stay and work in Canada for 2 years or more are able to accumulate the required months of full-time work experience to apply to PR under federal or provincial immigration streams. But others are ineligible to transition to PR because the duration of their work permit is too short to accumulate enough Canadian work experience. These citizens may try to extend their stay before their work permit expires by adopting a series of coping strategies, for example by seeking another employer willing to hire them under another program, but this is a risky process, especially when the transition is from an open to an employer-specific work permit. The privileged position of some IEC participants over others was acknowledged by a respondent from France: "Compared to other countries, it's great, because (...) with the two years, it allows (us) to apply for PR without having to change our visa" (Claire). Interviewees with shorter lengths of stay considered various strategies to seek PR, such as leaving Canada and returning with a tourist visa, launching an offshore application or being sponsored. Lucia, from Chile, explained:

"When my working holiday visa finished, I extended like visitor (...) then I went back to my country for five months and came back with a visitor visa again (...) He [the partner] said 'I can sponsor you'. Then, I went to see a lawyer, and he said, 'Okay you have to live together' (...) I started to live with him and now we are in the process for my permanent residency."

While previous studies have shown that TFWs' skill levels and types of work permit (open or employer-specific) constitute major factors facilitating or impeding the transition process in Canada (Nakache \& Dixon-Perera, 2015; Prokopenko \& Hou, 2018; Rajkumar et al., 2012), our research illustrates that the nationality of TFWs is also an important determinant. In fact, in the case of the IEC, a worker's nationality is the prevailing factor conditioning how much time he/she is allowed to stay in Canada, which effects how much work experience can be accumulated in order to meet the eligibility criteria for a PR program. Within a same entry category, nationality and its associated immigration conditions lead to inconsistent PR opportunities and differentiated PR experiences among participants. Some scholarship suggests that important variations in immigration rules, 
depending on partner countries, reflect a willingness to encourage the settlement of migrants seen as sharing cultural similarities with the destination society (Helleiner, 2017). This could be true, but there are also important inconsistencies in the length of authorized stay between partner countries who could be seen as "culturally compatible" with Canada (Helleiner, 2017, 314). The preferential treatment of French citizens over Belgian or US citizens, for example, could also just be an unintended consequence of the fragmented management of the IEC program.

Interestingly, when considering the primary motivations to apply for PR, only two (out of eight interview participants interested in PR) sought a permanent status to really settle (i.e. make their life) in Canada. Others explained that their motives were more for securing their migratory status and expanding their freedom of choice with regard to their future plans. For these participants, PR was thus not conceived as part of a long-term settlement process, but rather as the most convenient tool to extend their stay, "keep all the doors open" and give them the most flexibility in their decision-making once their work permits expired.

"The maximum time here is two years and within these two years, we would do the application for PR for letting us the opportunity to stay longer, we don't know yet if we are going to stay, whether it will please us or not, but we prefer to do the PR application when we will have enough months of working in order to be able to choose after if we stay." (Sandrine from France)

"[PR is] for being able to stay (...) We have 5 years to wait and see, it doesn't mean that we will stay... we don't know how things will turn out but having the opportunity to say we are not compelled to going back (...)" (Laura from France)

"PR it is 5 years and to renew it a second time, we only need to remain 2 years on the territory, overall, I'm ok for 5 years and I can go in other countries, this is what I want." (Fabien from France)

For IEC participants on an employer-specific work permit, transitioning to PR was also seen as a way to change employers and improve their conditions of employment: "[with the] CSQ [Quebec selection certificate for PR] I can tell myself, if there is a problem, I can go somewhere else because now, I'm a bit trapped [in my work]" (Claire from France).

While our sample size is very small, it shows that there are IEC workers who are actively pursuing PR but the opportunity to achieve this transition is very uneven. This imbalance illustrates how state policies produce a "temporarypermanent divide" (Rajkumar et al., 2012) between migrant workers of a same entry category. At one end of the spectrum, there are workers with a temporarily temporary status because their conditions of residence allow them to "climb the ladders" (Goldring \& Landolt, 2013, 2021) towards a more secure status by gaining PR. At the other end, we find IEC workers with more restrictive conditions of residence, which place them into the precarious position of being permanently temporary in Canada. 


\section{Conclusion}

Although the number of migrants entering into Canada through the IMP and the IEC has grown quickly over the last years, these programs have been subject to little scientific scrutiny. By exploring how the regulatory structure of the IEC frames employment patterns and immigration trajectories of youth migrant workers in Canada, our research calls into question the privileged and recreational dimensions traditionally associated with youth mobility schemes, revealing their linkages with temporary labour migration programs. While research on temporary and precarious migration documents how distinct entry categories produce various forms of (in)security of presence and access to entitlements in the destination country (Rajkumar et al., 2012; Goldring \& Landolt, 2013; Anderson, 2010), our study offers new insight by showing that different conditions of residence can also be institutionalized by a same entry category.

We demonstrated that the IEC has become a complex structure made up of numerous bilateral agreements, resulting in a fragmented administration and the coexistence of multiple regulatory frameworks that are difficult to navigate for migrant workers. This situation leads to three major problems. First, it creates inconsistencies between stated policy objectives and the experiences of IEC workers. The examples of WH makers' prioritization of work over tourism, and the fact that some IEC workers apply for permanent residence for the purpose of securing their status-as opposed to settling in Canada-highlight these discrepancies. Second, it shapes uneven pathways into precarious employment and immigration statuses. The opportunity to change employer, to access health coverage, to find a position matching one's qualifications and ensure job/income security, or to change from one status to another are all lines of differentiation among IEC workers that condition the extent of their precarity in Canada. Finally, we see a hierarchy of status among these workers because individuals from certain countries enjoy conditions of admission and stay offering them a way out of precarity (by gaining PR) while others face a range of restrictions impeding or complicating their access to a more secure status. Thus, the factors behind the differentiated legal status of temporary migrant workers in Canada are multiplying and are no longer limited to occupational classification (high-skill vs. low-skill migration streams).

As youth mobility schemes grow in importance and complexity, they blur the lines between precarious migration/privileged mobility, work/travel, low-skill/ high-skill, temporary/permanent migration and raise important questions: How can internal differences between youth workers be limited, knowing that youth mobility schemes are based on reciprocal bilateralism? Could the economic contribution of WH makers be better recognized, and in doing so, how can we ensure that they do not become a new pool of precarious migrants? How can we articulate youth mobility schemes with temporary and permanent migration policies to provide workers with legal pathways that reflect their immigration intentions? And more generally, what are the deeper implications of having a program such as the IEC, which is not presented in policy discourse as a work migration stream, but in practice has split into two pathways: one where (some) temporary workers are able to obtain stability through a permanent status, and another where the program provides a steady supply 
of flexible workers to bolster Canada's economy. Does this reveal a change within Canada's immigration system or is it just another illustration of Canada extending its economic interests into non-economic immigration streams (Boucher \& Gest, 2018; Boucher, 2020; Ellerman, 2020)? All these questions deserve to be discussed and investigated, especially given the increasing importance of international mobility programs in Canada and in several other countries. We hope therefore that our paper, by providing new insights into the evolution of international mobility schemes, will help start a much-needed discussion on their numerous implications, both for migrants and the destination societies.

Funding This research is part of the On the Move Partnership: Employment-Related Geographical Mobility in the Canadian Context, a project of the SafetyNet Centre for Occupational Health \& Safety Research at Memorial University. On the Move is supported by the Social Sciences and Humanities Research Council through its Partnership Grants funding opportunity (Appl ID 895-2011-1019), InnovateNL, Government of Newfoundland and Labrador, the Canada Foundation for Innovation and numerous university and community partners in Canada and elsewhere.

\section{Declarations}

Competing Interests The authors declare no competing interests.

\section{References}

Anderson, B. (2010). Migration, immigration controls and the fashioning of precarious workers. Work, Employment and Society, 24(2), 300-317.

Australia Department of Home Affairs. (2018). Working holiday maker visa program report. June and December 2017. Australian Government. https://www.homeaffairs.gov.au/research-and-statistics/ statistics/visa-statistics/visit. Accessed 31 Aug 2020

Boucher, A. K. (2020). How 'skill' definition affects the diversity of skilled immigration policies. Journal of Ethnic and Migration Studies, 46(12), 2533-2550.

Boucher, A. K., \& Gest, J. (2018). Crossroads. Comparative immigration regimes in a world of demographic change (p. 246). Cambridge University Press.

Business Development Bank of Canada (BDC). (2018). Labour shortage: Here to stay, September 2018. https://www.bdc.ca/en/documents/analysis_research/labour-shortage.pdf. Accessed 31 Aug 2020

Cerna, Lucie, \& Czaika, Mathias. (2016). European policies to attract talent: The crisis and highly skilled migration policy changes. In A. Triandafyllidou \& I. Isaakyan (Eds.), High-Skill Migration and Recession. Diasporas and Citizenship. Palgrave Macmillan, London.

Consterdine, E. (2019). Youth Mobility Scheme: The panacea for ending free movement? National Institute Economic Review, 248, 40-48.

Desjardins Group. (2019). Labour shortages in Quebec and Ontario: Which regions and economic sectors are most affected? Economic Studies, March 13, 2019. https://www.desjardins.com/ressources/ pdf/pv031319e.pdf. Accessed 28 Aug 2020

El Assal, K., \& Sweetman, A. (2016). A Primer on Canada's Foreign Workers. The Conference Board of Canada.

Ellerman, A. (2020). Human-capital citizenship and the changing logic of immigrant admissions. Journal of Ethnic and Migration Studies, 46(12), 2515-2532.

Employment and Social Development Canada (ESDC). (2014). Overhauling the Temporary Foreign Worker Program - putting Canadians first Report. Government of Canada.

Fang, Y., Chien, M., and Walters, G. (2020). Understanding the emerging Chinese working holiday market. Journal of Vacation Marketing, 1-14.

Gilbert, R. (2017). International Mobility Program (IMP). Recommendations for change. Policy Brief prepared for the Labourer's International Union of North America (LiUNA) (p. 12) 
Goldring, L., Berinstein, C., \& Bernhard, J. K. (2009). Institutionalizing precarious migratory status in Canada. Citizenship Studies, 13(3), 239-265.

Goldring, L., \& Landolt, P. (2021). From illegalised migrant towards permanent resident: Assembling precarious legal status trajectories and differential inclusion. Journal of Ethnic and Migration Studies. https://doi.org/10.1080/1369183X.2020.1866978

Goldring, L., \& Landolt, P. (2013). The conditionality of legal status and rights: Conceptualizing precarious non-citizenship in Canada. In L. Goldring \& P. Landolt (Eds.), Producing and Negotiating NonCitizenship: Precarious Legal Status in Canada (pp. 3-27). University of Toronto Press.

Haan, M., Yoshida, Y., Amoyaw, J., \& Iciaszczyk, N. (2020). Temporary foreign workers to permanent residents in Canada. International Migration. https://doi.org/10.1111/imig.12741

Hawthorne, L. (2010). How valuable is "Two-Step Migration"? labor market outcomes for international student migrants to Australia. Asian and Pacific Migration Journal, 19(1), 5-36.

Hélin, L. (2017). Le programme vacances-travail Canadien: Trajectoire expérientielle et usage du droit du travail. Master Thesis, Université du Québec à Montréal.

Helleiner, J. (2017). Recruiting the "culturally compatible" migrant: Irish working holiday migration and white settler Canadianness. Ethnicities, 17(3), 299-319.

Ho, C.-I., Lin, P.-Y., \& Huang, S.-C. (2014). Exploring Taiwanses working holiday-makers' motivations: An analysis of means-end hierarchies. Journal of Hospitality \& Tourism Research, 38(4), 463-486.

Immigration, francisation et intégration Québec (IFIQ). (2020). «Programme de l'expérience québécoise (PEQ) - travailleur étranger temporaire», Gouvernement du Québec. https://www.immigrationquebec.gouv.qc.ca/fr/immigrer-installer/. Accessed 6 Jan 2021

Immigration, Refugees, and Citizenship Canada (IRCC). (2021). Temporary Residents - International Mobility Program Work Permit Holders under International Experience Canada (IEC). IRCC Statistical Reporting Group, Government of Canada. Customized Data Request CR-21-0005.

Immigration, Refugees, and Citizenship Canada (IRCC). (2020a). Temporary residents: Temporary foreign worker program (TFWP) and international mobility program (IMP) work permit holders - monthly IRCC updates. Ottawa: Government of Canada. https://open.canada.ca/data/en/dataset/. Accessed 6 Jan 2021

Immigration, Refugees, and Citizenship Canada (IRCC). (2020b). International experience Canada: Who can apply. Ottawa: Government of Canada. https://www.cic.gc.ca/english/work/iec/eligibility. asp. Accessed 6 Jan 2021.

Immigration, Refugees, and Citizenship Canada (IRCC). (2019a). Evaluation of the international experience canada program. Ottawa: IRCC Evaluation Division, Government of Canada. https://www. canada.ca/en/immigration-refugees-citizenship/corporate/reports-statistics/evaluations/internatio nal-experience-canada-2019.html. Accessed 31 Aug 2020

Immigration, Refugees, and Citizenship Canada (IRCC). (2019b). IRCC Operational Instructions. "International mobility program: Labour Market impact assessment exemption codes". IRCC operational instructions and guidelines: Temporary resident program, temporary workers. Ottawa: Goverment of Canada. https:// www.canada.ca/en/immigration-refugees-citizenship/exemption-codes.html. Accessed 31 Aug 2020

Immigration, Refugees, and Citizenship Canada (IRCC). (2019c). IRCC Operational Instructions. "International Experience Canada [R205(b)] (exemption code C21)". IRCC Operational Instructions and Guidelines: Temporary Resident Program, Temporary Workers, Ottawa: Government of Canada. https://www.canada.ca/en/immigration-refugees-citizenship/corporate/publications-manuals/opera tional-bulletins-manuals/. Accessed 31 Aug 2020

Immigration, Refugees, and Citizenship Canada (IRCC). (2019d). 2019 Annual Report to Parliament on Immigration. Government of Canada.

Immigration, Refugees, and Citizenship Canada (IRCC). (2018). Temporary Residents - International Mobility Program Work Permit Holders under International Experience Canada (IEC). IRCC Statistical Reporting Group, Government of Canada. Customized Data Request CR-18-0522.

Landolt, P., \& Goldring, L. (2013). The social production of non-citizenship: The consequences of intersecting trajectories of precarious legal status and precarious work. In L. Goldring \& P. Landolt (Eds.), Producing and Negotiating Non-Citizenship: Precarious Legal Status in Canada (pp. 154174). University of Toronto Press.

Lu, Y., \& Feng, H. (2017). Transition from temporary foreign workers to permanent residents, 1990 to 2014. 389. Statistics Canada.

Marsden, S. (2018). Enforcing Exclusion. Precarious Migrants and the Law in Canada. The new precarisousness: Temporary migrants and the law in Canada. University of British Columbia Press.

Moving2Canada. (2021). International experience Canada. https://moving2canada.com/immigration/ canadian-work-permits/international-experience-canada/. Accessed 14 Jan 2021 
Nakache, D., \& Leanne, D.-P. (2015). “Temporary or transitional? Migrant workers' experiences with permanent residence in Canada”. 55. Montreal: Institute for Research on Public Policies.

OECD. (2019). International Migration Outlook 2019. Organisation for Economic Co-operation and Development.

OECD. (2016). Recruiting for success. Challenges for Canada's Labour Migration System. Organisation for Economic Co-operation and Development.

Office of the Auditor General of Canada. (2019). Reports of the auditor general of Canada to the parliament of Canada, Report 1 Call Centres, Independent Auditor's Report, Spring 2019, 27 p.

Oommen, E. (2019). Privilege and youth migration: Polarised employment patterns of youth mobility workers in London. Journal of Ethnic and Migration Studies, 1-17

Pellerin, H. (2017). States and the management of the international mobility highly skilled labour in the age of neoliberalism. International Journal Migration and Border Studies, 3(4), 352-367.

Procyk, S., Lewchuk, W., and Shields J. (2017). Precarious employment. Causes, consequences and remedies (p. 200). Fernwood Publishing: Black Point (Nova Scotia).

Prokopenko, E., \& Feng, H. (2018). How temporary were Canada's temporary foreign workers? 402. Statistics Canada.

Rajkumar, D., Berkowitz, L., Vosko, L. F., Preston, V., \& Latham, R. (2012). At the temporary-permanent divide: How Canada produces temporariness and makes citizens through its security, work, and settlement policies. Citizenship Studies, 16(3-4), 483-510.

RAMQ. (2020). «Conditions d'admissibilité à l'assurance maladie», Régie de l'assurance maladie du Québec, Gouvernement du Québec. https://www.ramq.gouv.qc.ca/fr/citoyens/assurance-maladie/ connaitre-conditions-admissibilite. Accessed 15 Jan 2021

Reilly, A., Howe, J., van den Broek, D., \& Wright, C. F. (2018). Working holiday makers in Australian horticulture: Labour market effect, exploitation and avenues for reform. Griffith Law Review, 27(1), 99-130.

Reilly, A. (2015). Low-cost labour or cultural exchange? Reforming the Working Holiday visa programme. The Economic and Labour Relations Review, 26(3), 474-489.

Rice, K. (2010). Working on Holiday": Relationships between tourism and work among young Canadians in Edinburgh. Anthropology in Action, 17(1), 30-40.

Roberston, S. (2014). Time and temporary migration: The case of temporary graduate workers and Working holiday makers in Australia. Journal of Ethnic and Migration Studies, 40(12), 1915-1933.

Shachar, A., \& Hirschl, R. (2013). Recruiting "super talent": The Nnew world of selective migration regimes. Indiana Journal of Global Legal Studies, 20(1), 71-107.

Smith, A., \& Staveley, J. (2014). Toward an ethnography of mobile tourism industry workers in Banff National Park. Anthropologica, 56(2), 435-447.

Standing, G. (2011). The precariat. The new dangerous class, Bloomsbury Academic.

Sweetman, A., \& Warman, C. (2014). Former temporary foreign workers and international students as sources of permanent immigration. Canadian Public Policy, 40(4), 391-407.

Tan, Y., \& Lester, L. (2012). Labour market and economic impacts of international working holiday temporary migrants to Australia. Population, Space and Place, 18, 359-383.

Uriely, N. (2001). Travelling Workers" and "Working Tourists": Variations across the interaction between work and tourism. International Journal of Tourism Research, 3, 1-8.

Vosko, Leah. (2020). Temporary labour migration by any other name: Differential inclusion under Canada's 'new' international mobility regime. Journal of Ethnic and Migration Studies, 1-25

Wilson, J., Fisher, D., \& Moore, K. (2010). The OE goes "home": Cultural aspects of a working holiday experience. Tourist Studies, 9(1), 3-21.

Yang, X., \& Wen, B. (2016). A study on the motivations and experience value of Chinese working holiday maker in New Zealand. Journal of Service Science and Management, 9, 347-360.

Yoon, K. (2015). A national construction of transnational mobility in the "overseas working holiday phenomenon" in Korea. Journal of Intercultural Studies, 36(1), 71-87.

Yoon, K. (2014). Transnational youth mobility in the neoliberal economy of experience. Journal of Youth Studies, 17(8), 1014-1028.

Zhu, H., Tucker, H., Duncan, T., \& Zhang, J. (2020). Young Chinese becoming working holiday makers in New Zealand: A thematic analysis of WHMs' motivations. Journal of China Tourism Research, 16(3), 406-423.

Publisher's Note Springer Nature remains neutral with regard to jurisdictional claims in published maps and institutional affiliations. 